Case Reports in Neurology
Case Rep Neurol 2020;12:76-83

DOI: $10.1159 / 000505908$

Published online: December 14, 2020
(C) 2020 The Author(s)

Published by S. Karger AG, Basel www.karger.com/crn

This article is licensed under the Creative Commons Attribution-NonCommercial 4.0 International License (CC BY-NC) (http://www.karger.com/Services/OpenAccessLicense). Usage and distribution for commercial purposes requires written permission.

\title{
Hyperperfusion Syndrome and Baroreflex Failure following Carotid Artery Angioplasty and Stenting for Symptomatic Radiation-Associated Carotid Artery Stenosis
}

\author{
Hui-Meng Chang \\ Department of Neurology, National Neuroscience Institute - Singapore General Hospital \\ Campus, Singapore, Singapore
}

\section{Keywords}

Radiation-associated atherosclerosis · Hyperperfusion syndrome $\cdot$ Baroreflex failure

\begin{abstract}
Cerebrovascular manifestations of radiotherapy for head and neck cancers are well described. In Southeast Asia, because nasopharyngeal cancer is common, patients with late cerebrovascular consequences are encountered regularly. This case report describes the long-term follow-up of a Chinese male patient with symptomatic severe radiation-associated atherosclerosis, who had carotid artery angioplasty and stenting performed, and the subsequent complications encountered: cerebral hyperperfusion syndrome, baroreflex failure, and progressive carotid artery stenosis.

(C) 2020 The Author(s)

Published by S. Karger AG, Basel
\end{abstract}

\section{Introduction}

Radiation therapy for head and neck cancers is associated with premature atherosclerosis involving the common, internal, and external carotid arteries as well as vertebral arteries, corresponding with the field of radiation [1]. This has been termed radiation-associated

Hui-Meng Chang
Department of Neurology
Singapore General Hospital, Outram Road
Singapore 169608 (Singapore)
chang.hui.meng@singhealth.com.sg




\section{Case Reports in Neurology}

Case Rep Neurol 2020;12:76-83

\begin{tabular}{l|l}
\hline DOI: 10.1159/000505908 & ○ 2020 The Author(s). Published by S. Karger AG, Basel \\
\hline
\end{tabular} www.karger.com/crn

Chang: Complications of Stenting with Radiation-Associated Carotid Artery Stenosis

atherosclerosis (RAA) because of phenotypic differences from standard atherosclerosis. In Southeast Asia, RAA due to prior radiation therapy for nasopharyngeal cancer (NPC) is encountered at regular intervals because of the prevalence of NPC in this region [2]. The preferred treatment for symptomatic severe RAA of the carotid artery is usually carotid artery angioplasty with stenting, because of underlying radiation dermopathy with increased risks of poor wound healing. Rare complications in the short term include hyperperfusion syndrome (HPS) and baroreflex failure (BRF), and in the long term, progressive atherosclerosis. This case report describes the 10-year follow-up of such a patient, who was also on warfarin for atrial fibrillation from ischaemic heart disease.

\section{Case Report}

This is a case report of a patient with RAA, with a 10-year follow-up. Mr. P. had radiotherapy for NPC in 2002. In December 2008, he presented with heart failure secondary to atrial fibrillation, and ischaemic heart disease was eventually diagnosed. Warfarin was started for atrial fibrillation and right atrial appendage clot, identified on transthoracic echocardiogram. His LDL cholesterol was $2.28 \mathrm{mmol} / \mathrm{L}$, and he was started on a statin.

In April 2009, he presented with left brachial paresis, with a therapeutic international normalized ratio (INR) of 2.4. Magnetic resonance imaging (MRI) of the brain revealed scattered, watershed infarcts between the right middle (MCA) and anterior (ACA) cerebral artery territories. Carotid artery duplex scan showed long plaques, along both common (CCA) to internal (ICA) and external carotid arteries, with the most severe stenosis over his right proximal ICA $(75-80 \%$ stenosis, mean velocity $[\mathrm{MV}]=275 \mathrm{~cm} / \mathrm{s}$, ratio of peak systolic velocities [PSV], ICA/CCA = 7.4), and a negative microemboli test after 30 min of monitoring over both MCAs. He was diagnosed with symptomatic and severe right radiation-associated carotid artery stenosis. Transcranial imaging confirmed patent flows intracranially; however, flows over the right anterior (MCA and ACA) circulation were 10-40\% lower than those over the contralateral left anterior circulation. There was also collateral support to the right MCA from a retrograde right ACA. The patient declined right carotid artery revascularization initially. By September 2009, his repeat duplex scan showed progression of stenoses over both his right mid CCA and proximal ICA (both were around 80\% stenoses, with MV 360 and $318 \mathrm{~cm} / \mathrm{s}$, respectively, and ratios of PSV CCA/CCA 15.3 and 13.4, respectively). Similarly, his left carotid plaques had also progressed from 50 to $60 \%$ stenoses. In the interim, he had also developed right hemispheric transient ischaemic attacks with recurrent left arm weakness and right ocular ischaemic symptoms, with emboli identified in his right retinal arteries.

Right carotid artery angioplasty and stenting (CAS) was performed in December 2009. He remained in hospital for 4 days to optimize blood pressure (BP) control. In hospital, his systolic BP ranged between 120 and $140 \mathrm{~mm} \mathrm{Hg}$. He was readmitted 2 days after discharge, with pain along the right side of his neck, up to his head. His BP was raised at $180 \mathrm{~mm} \mathrm{Hg}$, and brain CT showed scattered small right frontal and parietal infarcts with a small area of cerebral haemorrhage (Fig. 1). He was managed for cerebral HPS with an increased dose of ACE inhibitor and intravenous labetalol as needed, to maintain systolic BP below $140 \mathrm{~mm} \mathrm{Hg}$. After discharge, he continued home BP monitoring, and reported systolic BP ranging from 55 to 210 $\mathrm{mm} \mathrm{Hg}$. He was symptomatic at the extreme BP range, feeling giddy when low, and flushed when high. Clinic BP measurements showed similar wide variability, and he was eventually diagnosed with BRF in an irradiated neck, post-carotid artery stenting, after exclusion of

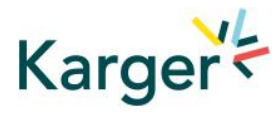




\section{Case Reports in Neurology}

Case Rep Neurol 2020;12:76-83

\begin{tabular}{l|l}
\hline DOI: 10.1159/000505908 & ○ 2020 The Author(s). Published by S. Karger AG, Basel \\
\hline
\end{tabular} www.karger.com/crn

Chang: Complications of Stenting with Radiation-Associated Carotid Artery Stenosis

endocrine abnormalities. He had 24-h ambulatory BP measurements in February 2011. His minimum and maximum awake BP were 71/46 and 239/125 mm Hg, respectively. His minimum and maximum sleep BP were 75/55 and 172/96 mm Hg, respectively. His pulse rate ranged between 45 and 61 beats per minute (bpm). In September 2012, an attempt was made to confirm BRF by measuring his bradycardic and tachycardic responses to pressor and vasodilator agents as previously described [3]. Intravenous phenylephrine was given to induce an increase in systolic BP ( $>36 \mathrm{~mm} \mathrm{Hg}$ achieved), but he did not have an appropriate drop in heart rate (heart rate remained at $85 \mathrm{bpm}$ ). Intravenous nitroprusside was given to induce hypotension, but his systolic BP and heart rates rose from $135 \mathrm{~mm} \mathrm{Hg}$ and $85 \mathrm{bpm}$, respectively, to $209 \mathrm{~mm} \mathrm{Hg}$ and $92 \mathrm{bpm}$, despite increasing nitroprusside doses, and this test was stopped after $48.4 \mu \mathrm{g}$ of nitroprusside. His BP and heart rate increased with mental math, but with the cold pressor test, only his BP rose. Advice had been given to manage the risk of falls. Therapeutic lifestyle changes, such as adequate hydration, leg stockings, and abdominal binders, and avoidance of over-the-counter pressor medications (that could contain vasoactive drugs) had also been advised. Clonidine and nitroglycerin patches were given for his BP surges and midodrine for hypotension - but did not provide symptomatic relief, as he reported unpredictable and rapid changes in BP with use. As Mr. P. also had atrial fibrillation, and was on warfarin with therapeutic INRs, there was concern about falls from symptomatic hypotension and bleeds from hypertension. Left atrial appendage occluder was considered but not performed as Mr. P. eventually learnt to recognize and manage his symptoms. By April 2013, a repeat 24-h ambulatory study confirmed some attenuation in his BP variability: his minimum and maximum wake BP were 79/49 and 159/120 $\mathrm{mm} \mathrm{Hg}$, respectively. His minimum and maximum sleep BP were 79/49 and 107/73 mm Hg, respectively, with pulse rates between 40 and $90 \mathrm{bpm}$. By 2014, his systolic BP were more muted, rarely exceeding $170 \mathrm{~mm} \mathrm{Hg}$, and by 2016, his home systolic BP ranged between 60 and $120 \mathrm{~mm} \mathrm{Hg}$, and he reported rare systolic BP surges.

He had regular duplex scans of his carotid arteries, and a mild intra-stent progressive stenosis was identified over his proximal right ICA in December 2010, that had progressed to severe 1 year later (MV $273 \mathrm{~cm} / \mathrm{s}$, PSV ICA/CCA = 7.9, residual lumen $1 \mathrm{~mm}$ ), but he remained asymptomatic. In August 2012, he had a symptomatic transient ischaemic attack, and the intra-stent stenosis had progressed further (MV $333 \mathrm{~cm} / \mathrm{s}$, PSV ICA/ CCA = 8.7). He was successfully stented in September 2012 (Fig. 2). Mr. P. has had no further neurological events since. As of October 2019, his duplex scan showed patent right carotid artery stents with mild $(<30 \%)$ intra-stent stenosis (Fig. 3), and his left carotid artery stenosis had progressed to an ulcerated plaque, causing about 70\% stenosis (MV $134 \mathrm{~cm} / \mathrm{s}$, PSV ICA / CCA = 3.2). In the early years, his LDL cholesterol had remained between 2.0 and $2.5 \mathrm{mmol} / \mathrm{L}$ during follow-up. In recent years, his LDL ranged between 1.75 and $2.25 \mathrm{mmol} / \mathrm{L}$.

\section{Discussion/Conclusion}

Mr. P. illustrates common to rarely encountered late cerebrovascular complications associated with radiotherapy for NPC - RAA, HPS, and BRF [1]. Other cancers requiring radiotherapy to the neck regions could present with similar problems, though in Southeast Asia, NPC is the most common cause.

NPC is common in Southeast Asia, Southern China, Hong Kong (Special Administrative Region), and Taiwan but rare in Western countries and Japan [2]. Radiotherapy is the

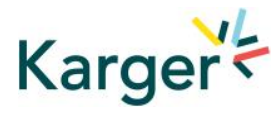




\section{Case Reports in Neurology}

Case Rep Neurol 2020;12:76-83

\begin{tabular}{l|l}
\hline DOI: 10.1159/000505908 & ๑ 2020 The Author(s). Published by S. Karger AG, Basel \\
\hline
\end{tabular} www.karger.com/crn

Chang: Complications of Stenting with Radiation-Associated Carotid Artery Stenosis

mainstay of treatment for NPC, and radiation fields involve the neck and lower half of the face. Both radiation and clinical factors contribute to the development of RAA $[1,4,5]$. It is believed that injury to the vasa vasorum and endothelial cells as well as radiation itself contribute to early development of atherosclerotic plaques in these patients [1]. Correlations have been found between RAA plaque load and increasing time interval after radiation, in a cohort of patients who were on average 2 years post-radiation [6]. Studies have shown that RAA is different from standard atherosclerosis in that RAA plaques are $[4,5,7,8]$ :

- significantly longer and more diffuse plaques, often extending from the CCA to ICA;

- more likely to be ulcerated, have mobile plaques or intraplaque haemorrhage;

- more likely to involve the ipsilateral external carotid artery and vertebral artery as well;

- more likely to have bilateral carotid artery involvement;

- more likely to progress in severity with time; and

- more likely to develop intra-stent stenosis after CAS.

The above findings were all present in our patient over his 10-year follow-up. While with a therapeutic INR for atrial fibrillation, his initial stroke presentation was already supportive of a symptomatic right severe carotid artery stenosis, with a watershed pattern of infarct seen on his brain scan. Over time, he developed ocular and hemispheric symptoms referable to progressive right carotid artery stenoses. He eventually had CAS. One year later, he developed intra-stent stenosis that progressed to severe within another year and continued to progress despite compliance with lifestyle changes, medical therapy, and LDL cholesterol levels that were mostly between 1.75 and $2.5 \mathrm{mmol} / \mathrm{L}$. Three years after his first CAS, he required another for symptomatic intra-stent severe stenosis. In these last 6 years, serial duplex scans continue to support the very gradual progression of stenoses. Radiation therapy creates a "hostile neck" with thickened fibrotic underlying tissue that has contributed to reports of more frequent wound complications and cranial nerve injuries with carotid artery endarterectomy [9]. Hence, many centres offer CAS instead.

Cerebral HPS was classically described as the triad of severe ipsilateral headaches, seizures, and intracranial haemorrhage following the correction of an ipsilateral high-grade carotid artery stenosis. It is attributed to the loss of vascular reactivity in the affected intracranial vessels that have been chronically dilated. The sudden improvement in blood flow, coupled with postoperative high BP, lead to cerebral oedema and sometimes intracerebral haemorrhage. Early support for this comes from studies that showed impressive increases in cerebral blood flows, up to 3-4 times, in affected patients [10-13]. It is a rare complication, occurring in $3.4 \%$ of patients post-carotid endarterectomy and $2.2 \%$ post-CAS in one meta-analysis [11]. There is no standard definition for cerebral HPS. Besides the clinical presentation, imaging criteria for documenting increased cerebral blood flows pre- and postoperatively have used different modalities and definitions (from transcranial studies to CT SPECT to perfusion MRI) [12]. CT or MRI brain scans may be normal or show focal oedema or haemorrhage. The majority of patients present within the first week, although it could occur up to 30 days later. Patients with bilateral severe carotid artery stenosis, impaired cerebrovascular reserve, and postoperative hypertension and hypotension are more likely to develop cerebral HPS [1113]. Intracranial haemorrhage is associated with a worse prognosis [11]. In the case of Mr. P., cerebral HPS had been anticipated because of his chronic bilateral severe stenoses with indirect evidence of impaired cerebrovascular reactivity (lower flow velocities over his right anterior circulation on transcranial Doppler). His systolic BP had been kept at around 120-140 $\mathrm{mm} \mathrm{Hg}$ for the 4 days he was hospitalized after CAS, and he was discharged when target BP were achieved with oral antihypertensives.

\section{Karger'=}




\section{Case Reports in Neurology}

Case Rep Neurol 2020;12:76-83

\begin{tabular}{l|l}
\hline DOI: 10.1159/000505908 & $\odot 2020$ The Author(s). Published by S. Karger AG, Basel \\
\hline
\end{tabular} www.karger.com/crn

Chang: Complications of Stenting with Radiation-Associated Carotid Artery Stenosis

$\mathrm{BRF}$ is a rare condition, characterized by labile BP. Patients are also sensitive to volume depletion and vasoactive drugs. In healthy individuals, baroreflexes are stretch receptors in the carotid arteries and aorta that sense vascular distension and changes in BP in the arteries. This information is relayed to the brainstem nuclei via the glossopharyngeal and vagal nerves, as part of the afferent limb. After processing the information, responses are sent out via the efferent limb of the baroreflex, through the parasympathetic or sympathetic pathways - to effect appropriate changes in the BP and heart rate, thereby maintaining constant BP. In radiation-related $\mathrm{BRF}$, there is usually damage to the afferent limb of the baroreflex, leading to labile BP $[3,14]$. The hallmarks of BRF are insufficient bradycardic response to pressor agents like phenylephrine and insufficient tachycardic response to vasodilator agents like nitroprusside [3]. Normal patients should decrease their heart rate to 7-21 bpm to a phenylephrine dose that increases the systolic BP $>20 \mathrm{~mm} \mathrm{Hg}$, and increase the heart rate to 9-28 bpm with a nitroprusside dose that decreases the systolic BP $>20 \mathrm{~mm} \mathrm{Hg}$ [3]. In addition, because the sympathetic efferents are usually intact, normal individuals will have increased BP and heart rate response to cold pressor stimulus and mental math [3]. There are many other tests to confirm BRF and exclude other causes (such as autonomic failure, paroxysmal tachycardia, and anxiety attacks). Besides blood tests to exclude secondary causes (like phaeochromocytoma and hyperthyroidism), these tests usually include ambulatory BP monitoring, cardiovascular responses (BP and heart rate) to Valsalva manoeuvre, as well as other more sophisticated tests, not easily available $[14,15]$. Our patient demonstrated inadequate tachycardic response to phenylephrine; however, we were unable to elicit any hypotensive response with nitroprusside and aborted the test. Laboratory tests and cardiac evaluations had excluded secondary causes. The patient's assessments were consistent with our clinical impression of BRF, which appeared to have been provoked by his first CAS. His wide BP fluctuations were of clinical relevance because he was anticoagulated for secondary stroke prevention from atrial fibrillation. In retrospect, we hypothesized that his BRF caused episodic high BP at home, contributing to the development of cerebral HPS. This was managed by inpatient control of BP followed by home BP monitoring with appropriate lifestyle adjustments. Clonidine, nitroglycerin patches, and midodrine were tried, without much self-reported benefit. Eventually, our patient's wide BP fluctuations attenuated with time. Mr. P. has completed 10 years of neurological follow-up and remains stable and independent.

\section{Statement of Ethics}

This research complies with the guidelines for human studies and was conducted ethically in accordance with the World Medical Association Declaration of Helsinki. The subject provided informed consent to publish his case.

\section{Conflict of Interest Statement}

The author has no conflicts of interest to declare.

\section{Karger'}




\section{Case Reports in Neurology}

\section{Funding Sources}

No funding was received for this study.

\section{Author Contributions}

Dr. Chang prepared and drafted the manuscript.

\section{References}

1 Bhandare N, Mendenhall WM. A literature review of late complications of radiation therapy for head and neck cancers: incidence and dose response. J Nucl Med Radiat Ther. 2012;S:2. DOI: 10.4172/2155-9619.S2009.

2 Mahdavifar N, Ghoncheh M, Mohammadian-Hafshejani A, Khosravi B, Salehiniya H. Epidemiology and Inequality in the Incidence and Mortality of Nasopharynx Cancer in Asia. Osong Public Health Res Perspect. 2016 Dec;7(6):360-72.

3 Robertson D, Hollister AS, Biaggioni I, Netterville JL, Mosqueda-Garcia R, Robertson RM. The diagnosis and treatment of baroreflex failure. N Engl J Med. 1993 Nov;329(20):1449-55.

$4 \mathrm{Xu}$ J, Cao Y. Radiation-induced carotid artery stenosis: a comprehensive review of the literature. Intervent Neurol. 2014 Aug;2(4):183-92.

5 Shichita T, Ogata T, Yasaka M, Yasumori K, Inoue T, Ibayashi S, et al. Angiographic characteristics of radiation-induced carotid arterial stenosis. Angiology. 2009 Jun-Jul;60(3):276-82.

6 Chang YJ, Chang TC, Lee TH, Ryu SJ. Predictors of carotid artery stenosis after radiotherapy for head and neck cancers. J Vasc Surg. 2009 Aug;50(2):280-5.

7 Yu SC, Zou WX, Soo YO, Wang L, Hui JW, Chan AY, et al. Evaluation of carotid angioplasty and stenting for radiation-induced carotid stenosis. Stroke. 2014 May;45(5):1402-7.

8 Huang MP, Fang HY, Chen CY, Tan TY, Kuo YL, Hsieh IC, et al. Long-term Outcomes of Carotid Artery Stenting for Radiation-Associated Stenosis. Biomed J. 2013 May-Jun;36(3):144-9.

9 Tallarita T, Oderich GS, Lanzino G, Cloft H, Kallmes D, Bower TC, et al. Outcomes of carotid artery stenting versus historical surgical controls for radiation-induced carotid stenosis. J Vasc Surg. 2011 Mar;53(3):62936.e1.

10 Reigel MM, Hollier LH, Sundt TM Jr, Piepgras DG, Sharbrough FW, Cherry KJ. Cerebral hyperperfusion syndrome: a cause of neurologic dysfunction after carotid endarterectomy. J Vasc Surg. 1987 Apr;5(4):62834.

11 Galyfos G, Sianou A, Filis K. Cerebral hyperperfusion syndrome and intracranial hemorrhage after carotid endarterectomy or carotid stenting: A meta-analysis. J Neurol Sci. 2017 Oct;381(381):74-82.

12 Huibers AE, Westerink J, de Vries EE, Hoskam A, den Ruijter HM, Moll FL, et al. Editor's Choice - Cerebral hyperperfusion syndrome after carotid artery stenting: A systemic review and meta-analysis. Eur J Vasc Endovasc Surg. 2018;(56):322-33.

13 Wang GJ, Beck AW, DeMartino RR, Goodney PP, Rockman CB, Fairman RM. Insight into the cerebral hyperperfusion syndrome following carotid endarterectomy from the national Vascular Quality Initiative. ] Vasc Surg. 2017 Feb;65(2):381-389.e2.

14 Heusser K, Tank J, Luft FC, Jordan J. Baroreflex failure. Hypertension. 2005 May;45(5):834-9.

15 Sharabi Y, Dendi R, Holmes C, Goldstein DS. Baroreflex failure as a late sequela of neck irradiation. Hypertension. 2003 Jul;42(1):110-6. 


\section{Case Reports in Neurology}

\begin{tabular}{l|l}
\hline Case Rep Neurol 2020;12:76-83 \\
\hline DOI: 10.1159/000505908 & $\begin{array}{l}\text { @ 2020 The Author(s). Published by S. Karger AG, Basel } \\
\text { www.karger.com/crn }\end{array}$ \\
\hline
\end{tabular}

Chang: Complications of Stenting with Radiation-Associated Carotid Artery Stenosis

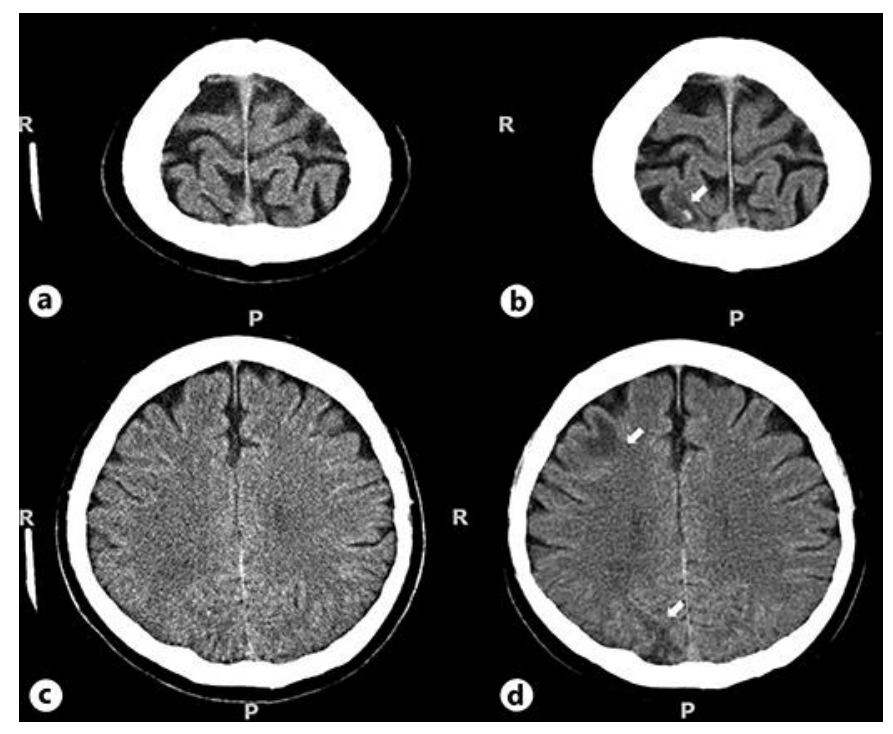

Fig. 1. Axial CT scan of the brain taken in April 2009 (images a and c) and December 2009 (images b and d). Images a and $\mathbf{c}$ were taken when the patient was first admitted with infarct, and images $\mathbf{b}$ and $\mathbf{d}$ were taken when the patient was diagnosed with cerebral hyperperfusion syndrome. Compared to image a, image $\mathbf{b}$ revealed a small focus of haemorrhage (small arrow) over the right superficial parietal area. Compared to image $\mathbf{c}$, image $\mathbf{d}$ showed infarcts (small arrows) over the right frontal and parietal lobes. 
Case Reports in Neurology
Case Rep Neurol 2020;12:76-83

DOI: 10.1159/000505908

(c) 2020 The Author(s). Published by S. Karger AG, Basel www.karger.com/crn

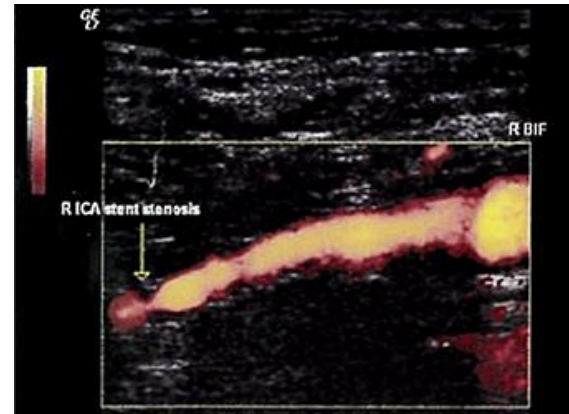

a
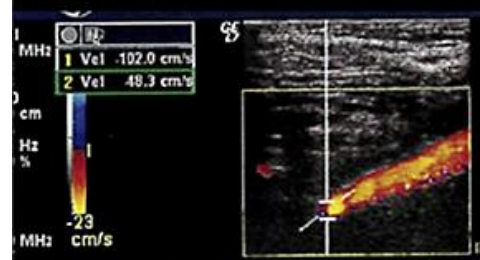

PICA DISTA

$\mathrm{K}_{\mathrm{KHz}}^{\mathrm{K}}$

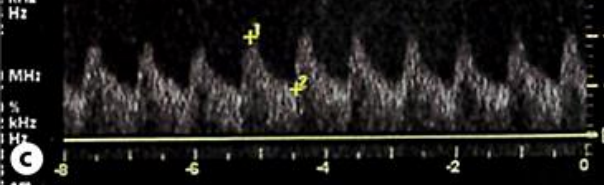

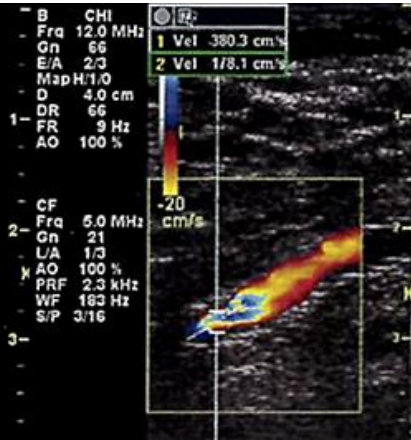

(b)

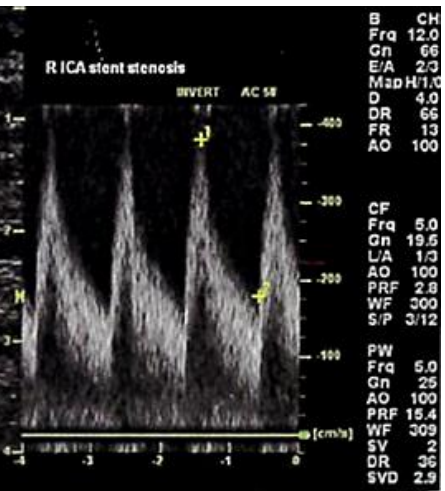

\section{:}
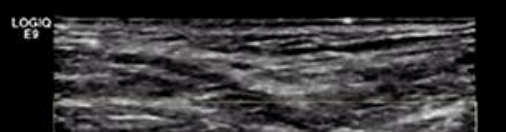

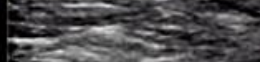
BST RICA

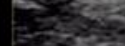

$3-$ -

Fig. 2. Angio mode with Doppler studies of right distal internal carotid artery intra-stent stenosis. Images a and $\mathbf{b}$ performed in December 2010 showed focal severe intra-stent stenosis with increase in velocities. Image c performed in October 2012 after right distal internal carotid artery angioplasty and stenting showed improvements in peak systolic velocities. Image d performed in October 2019 showed no significant intrastent stenosis.

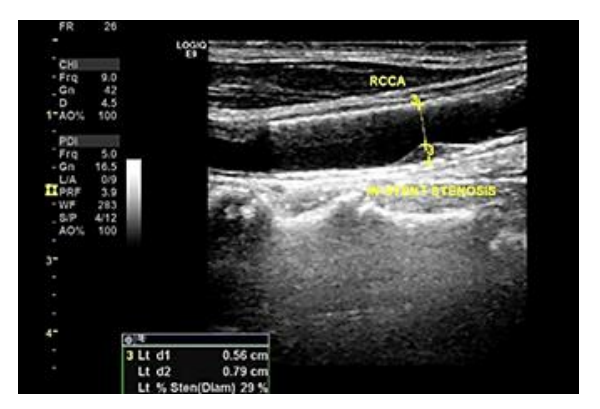

Fig. 3. B-mode Doppler of an intra-stent atherosclerosis, causing mild stenosis, in the right distal common carotid artery, taken in October 2019. 